\title{
DIVAGACIÓN SOBRE LOS OJOS: UNA MIRADA SIMBÓLICA AL CUERPO
}

\author{
Pedro José Díaz Camacho, O. P. \\ Universidad Santo Tomás
}

Recibido: febrero 7 de 2005

Aprobado: mayo 6 de 2005

\section{Resumen}

En este artículo se aborda el tema de los ojos desde una perspectiva humanista con el fin de hacer una reflexión acerca de algunas de nuestras "miopías". Para ello, se va mostrando cómo buena parte de la experiencia humana pasa a través de los ojos: la percepción de la realidad, la comunicación, etc. Se parte de un análisis de expresiones y metáforas de uso corriente que revelan el sentido y valor que damos a los ojos en la vida cotidiana. Se pasa luego a indagar por el papel de la mirada en el ámbito religioso, especialmente en el de los textos sagrados, y se reconoce a los ojos como protagonistas de la experiencia religiosa.

\section{Palabras clave}

Ojos, mirada

\begin{abstract}
In this article the theme of the eyes is tackled from the humanistic outlook aiming to make a thought about some of our 'short-sightedness'. In this order: it is shown how most of the human experiences go through the eyes: the perception of reality, the communication, etc. The starting point is the analysis of well-known expressions and metaphors that reveal the meaning and value we give to the eyes in daily life. Then, we go to inquire into the glance's role in the religious confines, specially in the sacred texts, and to recognize the eyes as main characters of religious experience.
\end{abstract}

\section{Key words}

Eyes, glance 
Y tú, Señor, por quien todos vemos y que ves las almas, dinos si todos, un día hemos de verte la cara.

A. Machado, "Iris de la noche” El ojo que ves no es ojo porque tú lo veas, -es ojo porque te ve.

A. Machado, "Proverbios y cantares"

\section{Preliminar}

En esta reflexión sobre los ojos humanos nos proponemos hacer una especie de divagación simbólica sobre los ojos desde un punto de vista diferente al propiamente biológico, científico y clínico, con el fin de abrir un espacio humanístico a la visión que podemos tener sobre el cuerpo humano, sus diversos componentes y sus variadas funciones. Este ejercicio pretende ayudarnos a reconocer algunas posibles miopías que tengamos sobre la manera de vernos a nosotros mismos en nuestra corporalidad o corporeidad.

Podemos comenzar reconociendo que gran parte de la experiencia humana, en sus múltiples aspectos e implicaciones, se desarrolla o se expresa en torno a los ojos y a su función de ver. En efecto, el contacto del hombre con gran parte de la realidad y su apropiación cognoscitiva, afectiva y práctica se obtiene por medio de la vista. Se dice que "el $80 \%$ de la información que recibimos del entorno es visual”. Así ocurre con la fe y el conocimiento, con el amor (como que hay amores a primera vista) y la alegría (que da brillo a los ojos), con el bien y la belleza, con el gozo y la tristeza. Todas estas en gran medida son formas de ver y de sentir la realidad, que de algún modo se percibe y pasa toda por los ojos, o se refleja en ellos, como quiera que los ojos son el reflejo o el espejo del alma en su sentido metafísico, psicológico, mental y espiritual.

La percepción visual de la realidad se ha expresado particularmente en el lenguaje popular, en la religión, en la música, en la literatura y en las demás formas del arte. Gran parte de la comunicación humana es netamente visual, ocular u óptica, para usar tres términos sinónimos de distinto origen y connotación. Por otra parte, la comunicación visual es una habilidad fundamental y de gran impacto en la relación interpersonal, especialmente en la comunicación de los sentimientos relacionados con la intimidad, la intimidación y la implicación. Todos sabemos, en efecto, lo que significa mirarse a los ojos para comprender que "más allá del ver está el mirar”, y que la profundización en este aspecto de la antropología nos conduciría a una “semiótica de la mirada”. Puesto que, como ha dicho un profesor:

El ver es natural, inmediato, indeterminado, sin intención; el mirar, en cambio es cultural, mediato, determinado, intencional. Con el ver se nace; el mirar hay que aprenderlo. El ver depende del ángulo de visión de nuestros ojos, el mirar está en directa relación con nuestra forma de socialización, con la calidad de nuestros imaginarios, con todas las posibilidades de nuestra memoria... Ver y mirar. El ver busca cosas; el mirar, sentidos $^{1}$.

1 Fernando Vásquez Rodríguez, "Más allá del ver está el mirar (pistas para una semiótica de la mirada)”, Signo y pensamiento (U. Javeriana, Bogotá) 20 (1992). 


\section{A ojo de buen cubero}

En el campo semántico de la metáfora, el lenguaje figurado del habla popular nos da muchas muestras del lugar, función, sentido y valor que tienen el ojo y la acción de ver en la experiencia humana. "Veamos" algunos ejemplos:

"Vamos a ver" se dice para indicar una acción que se quiere iniciar, para expresar una actitud de expectativa ante una realidad por venir o que se va a analizar; también ante un suceso y unos resultados que se esperan. "Vamos a ver qué pasa con la Facultad de Filosofía”.

Pero si la realidad a la que nos referimos es inesperada, incomprensible, paradójica, o generadora de dudas, se dice "Ver para creer" o "Vea, pues”. También: "Ya veremos”. Puede igualmente expresarse a modo de advertencia: “Ojo, que la vista engaña”.

Los acontecimientos fugaces y la apreciación de las acciones sucedidas con precipitud e inesperadamente, ocurren como "en un abrir y cerrar de ojos” o “a ojos vistas”. Pero si lo sucedido se refiere a algo negativo o funesto sobre lo cual ya no hay control ni solución, entonces se dice que "después del ojo afuera, no hay santa Lucía que valga”.

Si la realidad que nos ocupa no suscita grandes expectativas y es poco estimulante y apetecible o carente de interés y significado, se dice que "para lo que hay que ver, con un solo ojo basta”. Pero si esa realidad, por significativa que sea, no es percibida por los ojos, ni agradable al corazón o útil a nuestros intereses y propósitos, nos disculpamos diciendo: "ojos que no ven, corazón que no siente”. También se suele prevenir a alguien para que esté atento, analice y tome medidas oportunas, diciéndole que “abra bien los ojos”.
Si hay necesidad de mirar las cosas con detalle, cuidado y detenimiento, entonces podemos solicitar ayuda y afirmar que "cuatro ojos ven más que dos”, y no será suficiente “echar una ojeada” o contentarnos con "mirar de reojo”; será necesario “abrir bien los ojos”. A no ser que se trate de un asunto que requiera mucha discreción, y en tal caso se advertirá que "ni ojo en carta, ni mano en plata”.

Las relaciones éticas y jurídicas entre las personas se expresan también con la figura de los ojos, como que el odio y la venganza consisten en que uno "no puede ver" a alguien, o "no quiere verlo ni pintado", o le aplica la ley del talión: “ojo por ojo y diente por diente”. También procede la advertencia perentoria: “cría cuervos y te sacarán los ojos”. Pero a quien bien se quiere y se prefiere, se le cuida "como a las niñas de los ojos”; a los otros tal vez se les tenga “ojeriza”, o se les tenga “entre ojos” o se les "mire de reojo”, pero no se les “hará ojitos”.

Así, pues, si "los ojos son la luz o las ventanas del alma”, también ocurre que “por los ojos entran los antojos”; y se considera como un reconocimiento y elogio "tener ojo de águila o de lince” para ver las cosas desde lejos, en profundidad, con detalle, precisión y acierto. Esto implica “abrir bien los ojos” $\mathrm{y}$ "ver bien” para no equivocarse en las apreciaciones o decisiones, pero también estar atentos a lo que los otros ven porque, como a veces ocurre entre las parejas, "juzgan los enamorados que todos tienen los ojos vendados”, como le ocurre a la imagen que representa a la justicia.

Para seguir con el lenguaje popular, "amanecerá y veremos, como dijo el ciego”, porque, como "no hay peor ciego que el que no quiere ver”, es mejor ver las cosas con una mirada positiva y optimista para que lo que 
nos proponemos no nos llegue a "salir por un ojo de la cara”.

\section{Y vio que todo era bueno}

Algunos autores han dicho que la de los griegos era una religión de la visión y la de los hebreos una religión de la palabra, de la escucha. Pero en la religión de Israel también la acción de ver tiene gran importancia como forma de percibir, comprender e interpretar la experiencia de la relación del hombre con Dios y con el universo. Hay una manera de ver esa relación a través del simbolismo y el antropomorfismo de los ojos del cuerpo. El deseo de ver a Dios es una de las aspiraciones más persistentes de la humanidad religiosa y se refleja en toda la historia bíblica y en el ámbito de la espiritualidad. Los místicos la definieron como una "visión beatífica”, de alguna manera anticipada en las teofanías.

En el ámbito de la revelación bíblica, pues, podemos ver que desde el Génesis hasta el Apocalipsis la historia de la relación del hombre con Dios consiste básicamente en que el hombre quiere ver a Dios y busca su rostro, desde que ve la luz del mundo hasta que se apaga la luz de sus ojos, para luego ver a Dios tal cual es, en una “visión de paz”.

Cuando el libro sagrado habla sobre los orígenes de las cosas en términos de creación, utiliza un estribillo, al final de cada día de la actividad creadora: “y vio Dios que todo era bueno, todo lo que había hecho era bueno”. El ojo de Dios nos indica la medida del bien que hay en toda realidad, es una especie de optometría y de óptica teológica: a los ojos de Dios toda realidad es buena, y el ojo del hombre no ha de viciar la bondad de las cosas creadas por una visión equivocada o parcializada de las mismas.

Los grandes personajes de la historia bíblica fueron también videntes de Dios y visiona- rios de la historia humana porque veían la realidad a la luz de la experiencia de fe con los ojos de Dios. Y los grandes momentos de esa historia, en gran medida, se expresan como teofanías que manifiestan el poder de Dios, su santidad, su misericordia y su justicia. Pero se afirma igualmente que "a Dios nadie lo ha visto jamás” porque es un Dios escondido; e incluso se advierte que "nadie puede ver a Dios y seguir con vida”. De Él vemos sus obras.

Los “decanos” de la visión de Dios en la historia bíblica, que son los patriarcas y los profetas, son también los conductores del pueblo y los intérpretes de la historia. Moisés y Elías son visionarios privilegiados, y, como los primeros profetas, son videntes primero, $\mathrm{y}$ antes que mensajeros, son contemplativos que luego se hacen testigos y misioneros. Ellos buscaban “ver la gloria de Dios”, como máxima aspiración y cumplimiento de su experiencia religiosa.

De los ídolos o dioses falsos, que amenazan y extravían la fe del pueblo, se dice lo mismo que de los soberbios, incrédulos y descreídos: “tienen ojos y no ven”. En cambio, los que aguardan la salvación prometida y reconocen los signos de su llegada, se expresan como el viejo Simeón al contemplar a Jesús todavía niño: "mis ojos han visto la salvación”. Y uno de los signos para reconocer la cercanía y la irrupción del Reino de Dios en la historia que inaugura Jesús, es que "los ciegos ven”, como atestiguan las referencias evangélicas a la curación de los ciegos y a la iluminación que procede del Espíritu Santo para ver los caminos de Dios.

A Dios se le representa también como un gran ojo abierto y vigilante enmarcado en un simbólico triángulo, alusivo al misterio de la Trinidad. Según la enseñanza bíblica, Dios todo lo ve, hasta las entrañas del corazón, hasta los pensamientos más privados y recónditos. 


\section{Vengan y vean}

Los primeros discípulos de Jesús son llamados a una experiencia personal, directa y permanente: “vengan y vean”, les dice el Maestro; fueron, vieron y se quedaron con Él. Como discípulos, "vieron los signos que hacía”, signos "nunca antes vistos”.

Más tarde descubren en su proceso de fe, que en el hombre Jesús se revela, es decir, se quita el velo y permite ver la gloria o el poder de Dios; la plenitud de la divinidad se puede ver en Jesús; por eso decían: "hemos visto su gloria". "El que me ha visto, ha visto al Padre” (Jn. 14,9), decía Jesús a Felipe, quien le había solicitado con cierta premura: “muéstranos al Padre”.

Por algo los Evangelios relatan con especial cuidado y detalle las llamadas curaciones de los ciegos. La conversión de San Pablo, quien perseguía ciegamente a los cristianos, sucedió después de una experiencia de ceguera y de su curación. La visión es una condición indispensable de la fe y en cierta medida su equivalente, porque la fe es también una manera de ver; aunque al incrédulo Tomás se le reproche el no haber creído sin ver: "porque me has visto has creído. Dichosos los que sin ver han creído” (Jn. 20,29).

Cuando la polémica entre Jesús y los judíos se agudiza al final de su vida pública, Él les hace ver que siempre ha obrado y hablado abiertamente, que sus obras están a la vista. Pero como ellos pretenden sacar la paja del ojo ajeno sin ver la viga que hay en sus propios ojos, se enceguecen y llevan a Jesús a un juicio a todas luces injusto. No lo acusan por lo que han visto sino por lo que dicen haber oído. Lo que se ve parece más evidente e innegable que lo que se oye.

Y es curioso que cuando Jesús muere, ningún Evangelio dice que cerró los ojos, sino que "exhaló su espíritu”, que "expiró” (Mt. $27,50)$. Por eso, algunos crucifijos lo representan con los ojos abiertos dirigidos hacia el Padre, o con una mirada de misericordia hacia los hombres. Este detalle parece haberlo expresado magníficamente el misterioso artista que talló el milagroso Cristo de la Expiración que desde hace siglos se venera en la iglesia de Santo Domingo de Cartagena. Es un Cristo que, en el trance supremo de su expiración, mantiene los ojos abiertos buscando en los cielos la gloria del Padre. En el convento de Santo Eccehomo (cerca de Villa de Leyva) hay un Cristo que por ese mismo detalle de tener los ojos abiertos, es denominado por la gente "El Cristo vivo".

Todos sabemos que el último signo de vida en una persona agonizante queda reflejado en la falta de expresión de la pupila del ojo; $\mathrm{y}$, entonces, acudimos piadosamente y con temor, a cerrar sus ojos porque ya no verá más la luz. Brillará para él la luz perpetua y tendrá, por fin, acceso a la "visión de Dios", como anhelo supremo de su existencia creyente: "Véante mis ojos / dulce Jesús bueno; / véante mis ojos, / muérame yo luego", decía Santa Teresa de Jesús.

Al final de la historia humana, dicen los libros sagrados, "veréis venir al Hijo del Hombre en las nubes del cielo" (Ap. 1, 7). Y de los que no se salvan se dice que están privados de "la visión de Dios".

\section{Lo que hemos visto}

El comienzo de la misión cristiana, por la predicación de los apóstoles, se expresa como un testimonio de los que en primer lugar vieron a Jesús y vieron sus signos: "De lo que hemos visto, de eso hablamos"; "lo que hemos visto y oído, os lo anunciamos" (1 Jn. $1,3)$. El testigo ocular es quien tiene la auto- 
ridad para predicar el Evangelio. El que ha visto al Señor, puede hablar de Él y de sus obras con pertinencia y credibilidad.

El ojo humano es, pues, protagonista de gran parte de la experiencia religiosa, inclusive en las religiones de la palabra. Y lo es también de gran parte de la experiencia científica, artística, literaria y cultura.

Los ojos son una especie de divinidad omnipresente en la experiencia humana, y tienen todas las expresiones posibles: hay ojos tristes y llorosos, meditabundos y enamorados, alucinados, extraviados e impenetrables. La clarividencia nos permite ver más allá de lo que los ojos perciben.

Hay diagnósticos médicos, espirituales y sentimentales que se hacen con acierto a través de los ojos porque en ellos se concentra y refleja lo que vive el hombre y lo que lo desvive. Por lo que se refiere a la música, por ejemplo, bastaría con fijarnos en la cantidad de canciones de todo género que le cantan a los ojos, al ver y a la mirada, como objetos inspiradores del arte. Los músicos han expresado de múltiples maneras el insondable misterio que se asoma por los ojos del hombre y de la mujer en todas las circunstancias de la vida. También los poetas han visto con acierto y hondura que la vida se refleja en los ojos.

\section{Una nueva mirada}

Por todo lo anterior, se puede decir que quienes estudian científicamente el ojo humano, en su anatomía, su fisiología y sus patologías, y lo tratan médicamente, no pueden olvidar, pues, la forma simbólica y poética de ver este maravilloso universo que nos abre horizontes y panoramas inconmensurables e insospechados. Como lo expresó don Anto- nio Gómez Restrepo en su conocido poema "Los ojos":

Hay ojos soñadores y profundos que nos abren lejanas perspectivas; ojos cuyas miradas pensativas nos llevan a otros cielos y otros mundos.

Ojos, como el pesar, meditabundos, en cuyo fondo gris vagan esquivas bandadas de ilusiones fugitivas, como en el mar alciones errabundos. Ojos hay que las penas embellecen y dan filtro de celeste olvido a los que al peso de su cruz fallecen.

Ojos tan dulces como el bien que ha sido, y que en su etérea vaguedad parecen astros salvados del Edén perdido.

Julio Flórez, en “Tus ojos”, expresó también lo que los ojos significan, sugieren y reflejan:

Ojos indefinibles, ojos grandes, como el cielo y el mar, hondos y puros;

ojos como las selvas de los Andes: misteriosos, fantásticos y obscuros.

Ojos en cuyas místicas ojeras se ve el rastro de incógnitos pesares, cual se ve en la aridez de las riberas, la huella de las ondas de los mares.

Miradme con amor, eternamente, ojos de melancólicas pupilas, ojos que semejáis, bajo su frente, pozos de aguas profundas y tranquilas.

Miradme con amor, ojos divinos, que adornáis como soles su cabeza 
y encima de sus labios purpurinos. parecéis dos abismos de tristeza.

Miradme con amor, fúlgidos ojos, y cuando muera yo, que os amo tanto, verted sobre mis lívidos despojos, el dulce manantial de vuestro llanto.

Podemos recordar igualmente, a este propósito, el madrigal que inmortalizó al sevillano Gutierre de Cetina (siglo XVI):

Ojos claros, serenos, si de un dulce mirar sois alabados por qué, si me miráis, miráis airados?

Si quanto más piadosos, más bellos parecéis a aquel que os mira, no me miréis con ira, porque no parezcáis menos hermosos.
Ay, tormentos rabiosos.

Ojos claros, serenos,

ya que así me miráis, miradme al menos.

Y, para finalizar nuestra divagación, podemos exclamar con el poeta:

¡Cómo no haber amado sus grandes ojos fijos!

... su voz, su cuerpo claro. Sus ojos infinitos.

¡Ojos que a la luz se abrieron un día para, después, tornar a la tierra, hartos de mirar sin ver! (P. Neruda).

Si miramos bien, podremos ver más allá de lo que nuestros ojos ven. Hasta la vista. 